\title{
Effect of Water-Sediment Regulation of the Xiaolangdi Reservoir on the Concentrations, Bioavailability, and Fluxes of PAHs in the Middle and Lower Reaches of the Yellow River
}

\author{
Jianwei Dong ${ }^{a}$, Xinghui Xia ${ }^{*}$, Minghu Wang ${ }^{b}$, Yunjia Lai ${ }^{a, d}$, Pujun Zhao $^{a}$, Haiyang Dong ${ }^{a}$, Yunling Zhao $^{c}$, \\ Jiaojiao Wen $^{a}$ \\ ${ }^{a}$ State Key Laboratory of Water Environment Simulation / School of Environment, Beijing Normal University, \\ Beijing, 100875, China \\ ${ }^{b}$ AiShan Hydrological Station, Hydrology and Water Resources Survey Bureau of the Shandong Province, \\ Yellow River Conservancy Commission, Shandong, 252216, China \\ ${ }^{c}$ College of Chemistry, Beijing Normal University, Beijing, 100875, China \\ ${ }^{d}$ Agricultural and Environmental Chemistry Graduate Group, University of California, Davis, California 95616, \\ USA
}

\section{Abstract}

The water-sediment regulation of the Xiaolangdi Reservoir is conducted to control the relationship between riverine runoff and sediment transport of the Yellow River; however, there is no research about the effect of water-sediment regulation on the bioavailability and fluxes of hydrophobic organic compounds (HOCs). In this study, water and suspended sediment (SPS) samples were collected downstream of the Xiaolangdi Reservoir before, during, and after the water-sediment regulation in 2013. The 16 priority polycyclic aromatic hydrocarbon (PAH) concentrations of freely dissolved, total dissolved, and SPS-associated were determined. During water regulation, water discharged from the reservoir at a high flow rate led to the resuspension of downstream sediment. During sediment regulation, the sediment ejected from the reservoir resulted in higher SPS concentrations than that during water regulation. Both the freely and total dissolved PAH concentrations in river water during sediment regulation were the highest,

* Corresponding author. Tel.: +86 10 58805314; fax: +86 1058805314.

E-mail address: xiaxh@ bnu.edu.cn (X.Xia) 
followed by the concentrations during water regulation and before regulation. The freely dissolved PAH concentrations in river water during the water-sediment regulation were 2-11 times higher than those before water-sediment regulation. This was due to the fact that the resuspended sediment during water-sediment regulation could release PAHs into water phase, and more contaminants were released from the SPS during sediment regulation than during water regulation. The fluxes of sediment and the 16 priority PAHs $\left(\Sigma_{16} \mathrm{PAHs}\right)$ during water-sediment regulation contributed to $32.4 \%$ and $35.7 \%$ of their annual fluxes, respectively, which were higher than the contribution $(22.6 \%)$ of water discharge. This study suggested that the water-sediment regulation might reduce the long-term retention of sediment and PAHs in the reservoir. However, the environmental risk of PAHs as well as other contaminants downstream of the reservoir and in the estuary might increase during that period. Therefore, the effect of water-sediment regulation on the bioavailability and environmental risk of HOCs should be considered in the operation and management of the Xiaolangdi Reservoir in the future.

Keywords: Bioavailability, Polycyclic aromatic hydrocarbons (PAHs), Suspended Sediment (SPS), Dams, Water conservation project, Water quality 


\section{Introduction}

The transport and distribution of hydrophobic organic compounds (HOCs) in different phases of rivers greatly affect their bioavailability and water quality. Once the HOCs enter rivers, they are preferentially associated with suspended sediment (SPS) which may further deposit as bottom sediment. If there are changes in the hydrodynamic conditions, bottom sediment may resuspend, and the HOCs in the sediment can be released to the water. Therefore, bottom sediments could act as both sink and source of HOCs, and the hydrodynamic condition is the key factor influencing the transition between sink and source. Li et al. (2006) suggested that SPS processes play an important role in the distribution of polycyclic aromatic hydrocarbons (PAHs) in different sections of the Yellow River. In addition, many studies have found that sediment resuspension and deposition could change the freely dissolved concentrations of HOCs and alter their bioavailability in waters (Dong et al., 2013; Eggleton and Thomas, 2004; Friedman et al., 2009; Pedersen et al., 2002; Schneider et al., 2007). For example, Cornelissen et al. (2008) indicated that the resuspension of dredged sediment had increased the bioavailability of PAHs by a factor of 37.5 and polychlorinated biphenyls by a factor of 2.9 in the waters of Oslo harbor, Norway.

The hydrodynamic conditions of a river vary with many factors, including anthropogenic activities like dredging (Hayes et al., 2000; Je et al., 2007), trawling (Durrieu de Madron et al., 2005; Ferré et al., 2008), and operation of water conservation projects, and natural factors like wind, storm, and tide (Ferré et al., 2008; Pusceddu et al., 2005). Among these factors, water conservation projects play a key role in influencing the hydrodynamic conditions of a river. To efficiently utilize water resources, many water conservation projects, including hydropower stations, reservoirs, and dams, have been built around the world. They have remarkable impacts on hydraulic regulation and sediment retention in riverine system (Nilsson et al., 2005; Syvitski et al., 2005). However, there are few reports about the effect of water conservation projects on 
the bioavailability of HOCs and water quality of rivers.

Due to a high SPS concentration and different sources of water and sediment, water-sediment regulation of the Xiaolangdi Reservoir was conducted to solve the problem of imbalance between water and sediment for the Yellow River. The water-sediment regulation was divided into two periods: water regulation and sediment regulation. During water regulation, the overlying water with very little SPS was released from the Xiaolangdi Reservoir with a high flow discharge to scour the river channel and reduce SPS deposition. During sediment regulation, the bottom water containing as high as $300 \mathrm{~g} / \mathrm{L}$ of sediment was ejected from the Xiaolangdi Reservoir at a high flow rate to maintain reservoir capacity (Hu et al., 2012). From 2002 to 2013, water-sediment regulation had been operated 14 times. For each period, the average fluxes of water and sediment into the Bohai Sea were 3.8 billion $\mathrm{m}^{3}$ and 62.0 million tons, respectively (Zhang and Wang, 2012). However, there is no research about the effect of the water-sediment regulation of the Xiaolangdi Reservoir on the concentrations, bioavailability, and risk of HOCs downstream of the reservoir.

Therefore, the present study was conducted to investigate the effect of water-sediment regulation on the distribution and bioavailability of PAHs downstream of the Xiaolangdi Reservoir. The water and SPS samples were collected before, during, and after water-sediment regulation. The total dissolved concentrations of the sum of 16 priority PAHs $\left(\Sigma_{16} \mathrm{PAHs}\right)$ in the water phase and their concentrations in the SPS phase were analyzed. The freely dissolved concentrations of PAHs were measured by negligible depletion solid phase micro-extraction (nd-SPME) to reflect their bioavailability. The temporal and spatial variations of PAH concentrations in different phases were studied, and the effects of water regulation and sediment regulation on the bioavailability of PAHs were compared. In addition, the flux of PAHs into the Bohai Sea during water-sediment regulation was estimated. The effect of water-sediment regulation on the environmental risks of PAHs downstream of the Xiaolangdi Reservoir was also 
analyzed.

\section{2. Materials and methods}

92

93

94

95

96

97

98

99

100

101

102

103

104

105

106

107

108

109

110

111

112

\subsection{Chemicals and glassware}

3

Sixteen PAHs (naphthalene, acenaphthylene, acenaphthene, fluorene, phenanthrene, anthracene, fluoranthene, pyrene, benz(a)anthracene, chrysene, benzo(b)fluoranthene, benzo(k)fluoranthene, benzo(a)pyrene, indeno(123-cd)pyrene, dibenz(ah)anthracene, and benzo(ghi)perylene) and deuterated PAHs (d10-phenanthrene, d10-pyrene, and $d 12$-chrysene) were obtained from JT Baker (Philipsburg, NJ, USA). The physical-chemical properties of the studied PAHs are listed in Table S1 (Supplementary data). The recovery standard (2-fluorobiphenyl) and internal standard ( $m$-terphenyl) were obtained from J\&K Scientific Ltd. (New Haven, C.T., USA). HPLC grade dichloromethane (DCM), methanol, and hexane were supplied by J\&K Scientific Ltd. (New Haven, C.T., USA). All glassware was prepared as follows: soaked in an acid solution for $24 \mathrm{~h}$, afterward washed with tap water, distilled water, and ultrapure water (each for three times) in sequence; then dried in an oven $\left(105^{\circ} \mathrm{C}\right)$ and heated at $450^{\circ} \mathrm{C}$ in a muffle furnace for $4 \mathrm{~h}$.

\subsection{SPME preparation for the determination of freely dissolved PAHs}

Disposable glass fibers with a core of $110 \mu \mathrm{m}$ in diameter and coated with a $30-\mu \mathrm{m}$ layer of polydimethylsiloxane (PDMS) were obtained from Polymicro Technologies (Phoenix, Arizona, USA). Concentration of the PDMS coating was verified to be $13.55 \pm 0.02 \mu \mathrm{L} / \mathrm{m}$ fiber. The fibers were cut into required lengths $(1 \mathrm{~cm})$ with a quartz capillary cutting blade obtained from Polymicro Technologies. Then they were cleaned by sonicating in methanol and ultrapure water three times, and stored in ultrapure water before use.

The PDMS-water partition coefficients ( $\left.K_{\mathrm{PDMS}}, \mathrm{L} / \mathrm{L}\right)$ of PAHs serve as an essential 
113

114

115

116

117

118

119

121

122

parameter for determining freely dissolved PAH concentrations in the water phase. Our preliminary experiments indicated that the effect of temperature on the $K_{\text {PDMS }}$ was not significant in the range of $10-30^{\circ} \mathrm{C}$. However, spiking PAHs into ultrapure water (low ionic strength) led to significant underestimated $K_{\text {PDMS }}$ compared with previously reported values (Table S2). This might relate to the effect of ionic strength on PDMS-water distribution of HOCs (Jonker and Muijs, 2010). Therefore, in this study, artificial river water (ARW), containing $0.75 \mathrm{mM} \mathrm{NaHCO} 3,1.50 \mathrm{mM} \mathrm{CaCl}_{2}, 1.50 \mathrm{mM} \mathrm{MgCl}_{2}, 0.20 \mathrm{mM} \mathrm{KCl}$, and $0.50 \mathrm{mM}$ $\mathrm{NaN}_{3}$ in ultrapure water with a conductivity of $940 \mu \mathrm{s} / \mathrm{cm}$, was prepared to mimic the Yellow River water with a conductivity of $947 \pm 37 \mu \mathrm{s} / \mathrm{cm}$. The $K_{\mathrm{PDMS}}$ in the ARW was measured to determine the freely dissolved PAHs $\left(C_{\text {free }}, \mathrm{ng} / \mathrm{L}\right)$ with the following equation:

$$
C_{\text {free }}=\frac{C_{P D M S}}{\left(K_{P D M S} \times 10^{9}\right)}
$$

where $C_{\mathrm{PDMS}}(\mu \mathrm{g} / \mu \mathrm{L})$ is the PAH concentration in PDMS phase when the PAHs reach equilibrium between PDMS fiber and water phases. Details of the measurement of $K_{\mathrm{PDMS}}$ values are described in Supporting Information (SI 1.1), and $24 \mathrm{~h}$ was long enough for PAHs to reach equilibrium between PDMS fiber and water (Figure S1). $K_{\text {PDMS }}$ values measured in the present study (both ARW and ultrapure water) are listed in Table S2, which are comparable to previous reported values using the same type of PDMS fibers.

\subsection{Sample collection and pretreatment}

The Yellow River is more than $5400 \mathrm{~km}$ long with a drainage area of $752443 \mathrm{~km}^{2}$. The Xiaolangdi Reservoir is the last reservoir in the main river and the upstream drainage area occupies $92.3 \%$ of the Yellow River basin. The population of the Yellow River basin is 114 million, and the basin population downstream of the reservoir is 29 million. During water-sediment regulation in 2013 , water regulation occurred from June $19^{\text {th }}$ to July $3^{\text {rd }}$, and 
sediment regulation occurred from July $3^{\text {rd }}$ to July $10^{\text {th }}$. In this study, samples were collected before water-sediment regulation (June $15^{\text {th }}$ of 2013), during water regulation (June $22^{\text {th }}$, June $24^{\text {th }}$, June $26^{\text {th }}$, and June $28^{\text {th }}$ ), and during sediment regulation (July $4^{\text {th }}$ and July $8^{\text {th }}$ ). A total of six sampling sites were located along the middle and lower reaches of the Yellow River downstream of the Xiaolangdi Reservoir (Fig. 1), including Xiaolangdi (2 km downstream of the dam, XLD), Jiaogong Bridge (JG), Huayuankou (HYK), Aishan (AS), Luokou (LK), and Lijin (LJ). In addition, samples in the Xiaolangdi Reservoir (KQ) were collected at $0.5-1 \mathrm{~m}$ beneath the water surface on June $22^{\text {th }}$ during water regulation and July $4^{\text {th }}$ during sediment regulation to analyze the water quality of the reservoir.

To estimate the annual PAH flux of the Yellow River, the water and sediment discharges into the Bohai Sea were measured daily at LJ station. The velocity-area method described by Li et al. (2005) was used to determine water discharge. For the determination of sediment discharge, samples were collected using a DP-HSQ instantaneous type suspended sediment sampler. The details of the measurement are described in supporting information (SI 1.2). In addition, the PAH concentrations of the water samples collected on June $15^{\text {th }}$ (before water-sediment regulation) and September $20^{\text {th }}$ (after water-sediment regulation) at LJ station were determined.

Temperature, $\mathrm{pH}$, conductivity, and redox potential of the river water were determined in situ with a Mettler Toledo ${ }^{\mathrm{TM}}$ SevenGo meter (Mettler Toledo International, Schwerzenbach, Switzerland). The water sample was collected at each site with a $10 \mathrm{~L}$ pre-cleaned aluminum bucket. To analyze the SPS concentration, two liters of water sample were in situ filtered through a $0.45 \mu \mathrm{m}$ glass fiber membrane (Whatman, Maidstone, England), which was preheated at $60{ }^{\circ} \mathrm{C}$ and weighed at room temperature before use. After filtration, the glass fiber membranes were sealed with aluminium foil and transported to the laboratory within $48 \mathrm{~h}$. The membranes were placed in an oven at $60{ }^{\circ} \mathrm{C}$ until the samples were completely dried. Then each membrane was 
weighed again to calculate the SPS concentration of the water samples. The filtrate obtained in situ was used for the determination of total and freely dissolved concentrations of PAHs. In general, the total dissolved HOCs are operationally defined as the HOCs which can pass through a $0.45 \mu \mathrm{m}$ filter. The freely dissolved HOCs are commonly adopted to characterize their bioavailability. They are defined as the HOCs that are dissolved in the aqueous phase alone and in no way bound to any matrix (Pawliszyn, 1999). So the total dissolved HOCs include both the freely dissolved and the part combined with small colloids and dissolved organic carbon (DOC). As the total dissolved HOC concentration is not equivalent to its bioavailable concentration, SPME method was used to analyze the freely dissolved PAH concentrations in this study to better reflect the bioavailability of PAHs in river water during water-sediment regulation. The preliminary experiments indicated that the $0.45 \mu \mathrm{m}$ glass fiber membrane had no substantial effect on PAH concentrations. The total dissolved PAHs of each river water sample were extracted in situ by solid phase extraction (SPE) using Oasis HLB cartridges (Waters, Milford, MA, USA), which were pre-conditioned with $10 \mathrm{~mL} \mathrm{DCM,} 4 \mathrm{~mL}$ methanol, and $4 \mathrm{~mL}$ ultrapure water successively before extraction. Two liters of the filtered water sample with $50 \mathrm{ng} / \mathrm{L}$ 2-fluorobiphenyl were transferred to a 2.5 L-glass bottle, and a total of $100 \mathrm{~mL}$ methanol was added to enhance PAH extraction recoveries. Then the water sample in each bottle was passed through a SPE cartridge at a speed of $5 \mathrm{~mL} / \mathrm{min}$. After that, all the cartridges were subject to freeze-drying for over $72 \mathrm{~h}$ to remove moisture. Then the PAHs in each cartridge were eluted three times with $6 \mathrm{~mL}$ DCM each time. The eluents were combined, concentrated, and solvent-exchanged to $1 \mathrm{~mL}$ hexane under a soft nitrogen stream prior to GC/MS analysis.

In terms of freely dissolved PAHs, one piece of $1 \mathrm{~cm}$ pre-cleaned PDMS fiber was introduced into each brown jar containing $800 \mathrm{~mL}$ of filtrate as obtained above. The jars were sealed with Teflon ${ }^{\circledR}$ caps and placed on a horizontal shaker at $120 \mathrm{rpm}$ under $25{ }^{\circ} \mathrm{C}$ for $24 \mathrm{~h}$. Upon equilibrium, fibers were removed from the jars, wiped dry with ashless paper, and placed in 
$200 \mu \mathrm{L}$ hexane (containing $5 \mathrm{ng}$ of $m$-terphenyl as internal standard) for $24 \mathrm{~h}$ re-extraction of the PDMS-sorbed analytes before instrumental analysis. To confirm the feasibility of the nd-SPME method, the polyethylene devices (PEDs), which have been described in our previous work (Xia et al., 2013a) and Supplementary Information (SI 1.3), were suspended in river water to determine the freely dissolved concentrations of phenanthrene, pyrene, and chrysene in situ. According to the results shown in Figure S2, there was no significant difference between the freely dissolved concentrations of PAHs based on the PDMS placed in bottles and those based on the PEDs placed in river water; this indicated that the freely dissolved PAH concentrations in the water samples measured by nd-SPME could reflect the field concentrations.

For the determination of PAHs in SPS, a total of $2 \mathrm{~g}$ freeze-dried SPS sample was extracted using an accelerated solvent extractor (ASE300, Dionex Corp., USA). Each sample was extracted twice (under $100{ }^{\circ} \mathrm{C}$ and $\left.1500 \mathrm{psi}\right)$, using $66 \mathrm{~mL}$ hexane-acetone $(1: 1, \mathrm{v} / \mathrm{v})$ for each time. Then the total extract was concentrated by a rotary evaporator and solvent exchanged with $5 \mathrm{~mL}$ of hexane before the clean-up procedure. The detail of the clean-up procedure can be found in our previous study (Liu et al., 2010). After that, samples were concentrated below $1 \mathrm{~mL}$ under a nitrogen stream prior to GC/MS analysis.

\subsection{Calculation of PAH flux of the Yellow River}

Because the Lijin station is the last hydrometric station before the Yellow River flows into the Bohai Sea, water and sediment discharges as well as the fluxes of PAHs were calculated with the data obtained at the Lijin station in this study. The annual water discharge $\left(D_{W}\right)$ and annual sediment discharge $\left(D_{S P S}\right)$ were calculated as follows:

$$
D_{W}=\sum_{j=1}^{365} Q_{W j}
$$




$$
D_{S P S}=\sum_{j=1}^{365} Q_{S P S j}
$$

where $Q_{W j}$ and $Q_{S P S j}$ are the daily water and sediment discharges at LJ station, respectively. The water discharge before $\left(D_{W b}\right)$, during $\left(D_{W d}\right)$, and after $\left(D_{W a}\right)$ water-sediment regulation as well as the sediment discharge before $\left(D_{S P S b}\right)$, during $\left(D_{S P S d}\right)$, and after $\left(D_{S P S a}\right)$ water-sediment regulation were also calculated. The annual PAH flux $\left(F_{T}\right)$ of the Yellow River could be estimated with the follow equation:

$$
F_{T}=F_{D}+F_{B}+F_{A}
$$

where $F_{D}, F_{B}$, and $F_{A}$ are the PAH fluxes during, before, and after water-sediment regulation, respectively. The $F_{D}$ (lasting for 22 days) can be estimated with the following equation:

$$
F_{D}=\sum_{i=1}^{22}\left(C_{W i} \times Q_{W i}\right)+\sum_{i=1}^{22}\left(C_{S P S i} \times Q_{S P S i}\right)
$$

where $C_{W i}$ and $C_{S P S i}$ are the concentrations of $\sum{ }_{16}$ PAHs in the water and SPS phases on the $i^{\text {th }}$ day, respectively; $Q_{W i}$ and $Q_{S P S i}$ are the water and sediment discharges into the sea on the $i^{\text {th }}$ day, respectively, which were determined with daily measured data. Because the concentrations of $\sum_{16} \mathrm{PAHs}$ in samples were not determined daily, the PAH concentrations of June $19^{\text {th }}-21^{\text {th }}$ and $23^{\text {th }}$ were interpolated by those of June $22^{\text {th }}$, June $25^{\text {th }}$ by June $24^{\text {th }}$, June $27^{\text {th }}$ by June $26^{\text {th }}$, June $29^{\text {th }}$-July $3^{\text {rd }}$ by June $28^{\text {th }}$, July $5^{\text {th }}-$ July $7^{\text {th }}$ by July $4^{\text {th }}$, and July $9^{\text {th }}-10^{\text {th }}$ by July $8^{\text {th }}$. The $F_{B}$ and $F_{A}$ were estimated as follows:

$$
\begin{aligned}
& F_{B}=C_{W b} \times D_{W b}+C_{S P S b} \times D_{S P S b} \\
& F_{A}=C_{W a} \times D_{W a}+C_{S P S a} \times D_{S P S a}
\end{aligned}
$$

where $C_{W b}$ and $C_{W a}$ are the total dissolved concentrations of $\sum_{16} \mathrm{PAHs}$ in the river water before and after water-sediment regulation; $C_{S P S b}$ and $C_{S P S a}$ are the concentrations of $\sum_{16} \mathrm{PAHs}$ in the 
SPS before and after water-sediment regulation. Here we used the data obtained on June $15^{\text {th }}$ and on September $20^{\text {th }}$ to represent the values before and after water-sediment regulation, respectively.

\subsection{GC/MS analysis of PAHs}

PAHs were analyzed using a Varian 3800 gas chromatography-4000 ion trap mass spectrometry (GC/MS) system equipped with a Varian FactorFour ${ }^{\mathrm{TM}}$ highly inert capillary column VF-5ms $(30 \mathrm{~m} \times 0.25 \mathrm{~mm}$ diameter, and $0.25 \mu \mathrm{m}$ film thickness). The injection port temperature was maintained at $280^{\circ} \mathrm{C}$. Highly purity Helium $(99.9999 \%)$ was used as the carrier gas and kept at a constant flow rate of $1.0 \mathrm{~mL} / \mathrm{min}$. Sample extracts $(1.0 \mu \mathrm{L})$ were injected in splitless mode. The GC oven temperature was held at $80^{\circ} \mathrm{C}$ for $2 \mathrm{~min}$, then ramped at $15^{\circ} \mathrm{C} / \mathrm{min}$ to $230^{\circ} \mathrm{C}$ and held for $2 \mathrm{~min}$. The temperature was then programmed to increase to $290^{\circ} \mathrm{C}$ at $8^{\circ} \mathrm{C} / \mathrm{min}$ and held for $2 \mathrm{~min}$. Ionization was performed in electron impact (EI) mode and the ion source temperature was fixed at $200{ }^{\circ} \mathrm{C}$. For identification of each target chemical, full scan mode from 35 to 550 amu was first performed and identification was based on both retention time and characteristic ions. The quantification of each individual PAH and recovery standard was calculated based on internal standard method using the Varian WorkStation software.

\subsection{Organic carbon, black carbon, and particle size analysis}

For the determination of DOC in water sample, a total of $40 \mathrm{~mL}$ of the supernatant was transferred into a brown sample bottle. The DOC concentration was determined by an elemental analyzer (Vario El, Elementar Analysensysteme GmbH, Germany). The contents of total organic carbon (TOC) and black carbon (BC) of the SPS samples were also determined by the elemental analyzer after they were pretreated with the method as described in our previous work (Liu et al., 2010). In addition, the particle size of each SPS sample was determined with a Microtrac S3500 


\subsection{Quality assurance/quality control}

The correlation coefficients for calibration curves of PAHs with GC/MS were all higher than 0.99. The method detection limits (MDLs) of PAHs in water samples ranged from 0.4 to $6.5 \mathrm{ng} / \mathrm{L}$ method $(\mathrm{MDL}=$ mean+3SD). The PAHs in blank SPME fibers and SPE cartridges were below detection limits. As shown in Table S4, the recoveries of 16 PAHs and 2-fluorobiphenyl in spiked solution, spiked SPS, and spiked polyethylene ranged from $80.5 \%$ to $105.4 \% \quad(\mathrm{~N}=36)$, from $72.1 \%$ to $95.9 \%(\mathrm{~N}=48)$, and from $62.1 \%$ to $75.9 \%(\mathrm{~N}=24)$, respectively. The recovery of 2-fluorobiphenyl, which was used as recovery standard, ranged from $74.8 \%$ to $90.2 \%$ in real water samples, from $65.9 \%$ to $89.3 \%$ in real SPS samples, and from $60.2 \%$ to $79.8 \%$ in polyethylene samples. All the data were corrected with the recoveries of recovery standard. The use of SPME achieved a depletion ratio of less than $1.8 \%$ of the freely dissolved concentrations for the 16 PAHs in water, which was less than $5 \%$ and could be considered negligible. A 24-h extraction of the PDMS fibers was long enough for PAHs to desorb from PDMS, and the results showed that no PAHs were detected in a second extraction of fibers using $200 \mu \mathrm{L}$ fresh hexane. All the samples were in triplicate, and the results are expressed as average \pm standard deviation.

\section{Results and discussion}

\subsection{Effect of water-sediment regulation on PAH concentrations in different}

\section{phases}

\subsubsection{Total and freely dissolved PAHs in the water phase}

As shown in Figure 2, the total dissolved concentrations of $\sum_{16} \mathrm{PAHs}$ in river water before water-sediment regulation were lower than those during water regulation, and much lower than 
those during sediment regulation for each sampling site $(\mathrm{p}<0.05)$. For example, the total 275 dissolved concentration of $\sum_{16} \mathrm{PAHs}$ at $\mathrm{JG}$ station was $149 \pm 56.3 \mathrm{ng} / \mathrm{L}$ before water-sediment regulation, and it increased to $256 \pm 32.6 \mathrm{ng} / \mathrm{L}$ during water regulation and $608 \pm 69.7 \mathrm{ng} / \mathrm{L}$ during sediment regulation. The reason could be analyzed as follows. During water regulation, the water discharged from the reservoir at a high flow rate led to the resuspension of downstream sediment. During sediment regulation, the sediment ejected from the Xiaolangdi Reservoir resulted in high SPS concentrations downstream of the reservoir. Both the resuspended sediment during water regulation and the sediment ejected from the reservoir during sediment regulation could release contaminants into the water phase, leading to the higher total dissolved concentrations of $\sum{ }_{16} \mathrm{PAHs}$ during water-sediment regulation than those before water-sediment regulation. In river water during sediment regulation were higher than those during water regulation, and much higher than those before regulation (Figure 2). For example, the freely dissolved pyrene concentrations during water regulation and sediment regulation were 2 and 7 folds higher than those before regulation, respectively. The freely dissolved concentration of HOCs is commonly used as an indicator of their bioavailability (Wang et al., 2011; Xia et al., 2013b). Therefore, the water-sediment regulation could increase the concentrations of bioavailable PAHs downstream of 297 the reservoir. As shown in Figure S4, the ratios of freely to total dissolved concentrations of $\sum_{16} \mathrm{PAHs}$ were $53.6 \pm 16.2 \%$ before water-sediment regulation, $60.5 \pm 16.3 \%$ during water 
regulation, and $52.4 \pm 18.4 \%$ during sediment regulation. The results indicated that there was no

300 significant difference in the ratios among the three periods. Furthermore, the ratios of freely to 301 total dissolved concentrations of phenanthrene (60.6 $\pm 11.6 \%)$, pyrene $(39.8 \pm 25.6 \%)$, and chrysene $302(23.7 \pm 8.1 \%)$ obtained in this research were comparable to those of the Yongding River, the Haihe

303 River, and the Yellow River in our previous study (Xia et al., 2013a).

\subsubsection{PAHs in the SPS phase}

The PAH concentrations in the SPS during sediment regulation were higher than those during water regulation at each sampling site (Figure 2). This might be attributed to the fact that the SPS during sediment regulation was from the sediment of the Xiaolangdi Reservoir (KQ) and the SPS during water regulation was from the sediment downstream of the reservoir; these two sediments from different sources had different PAH concentrations, with the former higher than the latter (Figure S7). Besides, as shown in Table 1, the particle size of the SPS during sediment regulation was smaller than that during water regulation, and the TOC contents of the SPS of the former were higher than the latter. That is to say, the SPS during sediment regulation had larger specific surface areas and more sorption sites. Therefore, after desorption caused by sediment resuspension, the PAH concentrations in unit SPS during sediment regulation were still higher than those during water regulation. Feng et al. (2008) and Yang et al. (2008) have conducted simulation experiments to study the PAH release during sediment resuspension, and found that the PAH concentrations in SPS increased with the decrease of SPS particle size.

\subsubsection{Distribution of PAHs between the SPS and water phases}

The distribution coefficient $\left(K_{d}, \mathrm{~L} / \mathrm{kg}\right)$ of each PAH between the SPS and water phases was calculated with the following equation:

$$
K_{d}=C_{s} / C_{w}
$$

where $C_{s}$ is the PAH concentration in the SPS phase $(\mathrm{ng} / \mathrm{kg})$, and $C_{w}$ is the total dissolved PAH 
concentration in the water phase (ng/L). The OC-normalized distribution coefficient $\left(K_{O C}\right)$ was calculated by the following equation:

$$
K_{O C}=K_{d} / f_{o c}
$$

where $f_{o c}$ is the TOC content of SPS $\left(\mathrm{kg}_{O C} / \mathrm{kg}_{S P S}\right)$. As shown in Figure S5, there was no significant difference in the $\log K_{d}$ value for each PAH between sediment regulation and water regulation periods ( $\mathrm{p}>0.1$ ). However, the $\log K_{O C}$ value of each PAH during sediment regulation was lower than that during water regulation (Table 3). In general, the $K_{d}$ values are affected by the contents and composition of TOC in SPS as well as PAH characteristics, while the $K_{O C}$ values are influenced by the TOC composition (such as BC content) and PAH characteristics. In this study,

332 the BC contents of SPS increased from XLD to LJ during water regulation, while keeping 333 constant during sediment regulation. Furthermore, the $\mathrm{BC}$ contents during sediment regulation were lower than those during water regulation (Table 1); this resulted in the higher $\log K_{O C}$ values of PAHs during water regulation because the sorption capacity of $\mathrm{BC}$ is higher than amorphous organic carbon (Accardi-Dey and Gschwend, 2003). In addition, the increased BC during water regulation inferred that the PAHs associated with SPS were less bioavailable than during 338 sediment regulation. Besides, the OC-normalized distribution coefficients of PAHs obtained in 339 this study were comparable to those between SPS and water in the Xijiang River reported by 340 Deng et al. (2006). In addition, as shown in Figure S6, there is a positive relationship between log $341 K_{O C}$ and $\log K_{O W}$ values $(\mathrm{p}<0.01)$, suggesting that the characteristics of PAHs are the main factor 342 for their distribution between SPS and river water during water or sediment regulation.

\subsection{Spatial variation of PAH concentrations during water-sediment regulation}

As shown in Figure 3, during water regulation, the total and freely dissolved PAH concentrations in the water of the Xiaolangdi Reservoir were lower than those downstream of the reservoir except for HYK on June $22^{\text {th }}$, LK on $24^{\text {th }}$, and LJ on $24^{\text {th }}$ and $28^{\text {th }}$. In addition, for both 
total and freely dissolved PAH concentrations, the average values of the six sampling sites

348 downstream of the reservoir were higher than those of the reservoir for each sampling. During 349 sediment regulation, the total and freely dissolved PAH concentrations in the water of the reservoir were lower than those downstream of the reservoir for each sampling. There was a slightly decreasing trend in both total and freely dissolved concentrations of PAHs along the river downstream of the reservoir from June $26^{\text {th }}$ to July $8^{\text {th }}(\mathrm{p}<0.05)$, with only small disorders at the HYK and AS stations (Figure 3). The reason can be analyzed as follows. During water regulation, the PAH concentrations in SPS increased from XLD to LJ by 17\%-81\% (Figure S7). Furthermore, the particle size of the SPS decreased and the BC contents of SPS increased from XLD to LJ (Table 1). Therefore, the PAHs might be released from the coarse particles and then re-sorbed by the smaller particles with higher BC contents along the river, resulting in the decrease of PAH main river ( $\mathrm{Li}$ et al., 2006), which will lead to the slight increase of PAH concentrations in river

There are several tributaries downstream of the Xiaolangdi Reservoir. The Yiluo River and the Qin River flow into the Yellow River between JG and HYK; the Jindi River and the Dawen River flow into the main river between HYK and AS. The contributions of their annual water discharge and sediment discharge to the Yellow River are only $8.3 \%$ and $0.3 \%$, respectively, and the PAH concentrations in the river water of the tributaries are slightly higher than those of the water of the main stream. This might be the reason for the small disorders of PAH concentrations 
in the water phase along the river mentioned above.

\subsection{Flux of PAHs during water-sediment regulation}

\subsubsection{PAH flux into the Bohai Sea}

During water-sediment regulation, the water discharge into the Bohai Sea at the Lijin station was 5.3 billion $\mathrm{m}^{3}$ and the sediment discharge was 56.1 million tons. The fluxes of PAHs in the dissolved and particulate phases were estimated at 1.06 tons and 10.03 tons, respectively. Therefore, the total flux of PAHs during water-sediment regulation was 11.1 tons, and the PAH flux in the total dissolved phase contributed to $9.5 \%$. Before water-sediment regulation (during January $1^{\text {st }}$-June $18^{\text {th }}$ ), the water and sediment discharges were 6.5 billion $\mathrm{m}^{3}$ and 13.1 million tons, respectively, and the PAH flux was 1.8 tons including 0.8 tons in dissolved phase. After regulation, the water and sediment discharges were 11.5 billion $\mathrm{m}^{3}$ and 103.7 million tons, respectively, and the PAH flux was 18.2 tons including 2.7 tons in dissolved phase. Therefore, the annual flux of PAHs was the sum of the three periods, which was estimated to be 31.1 tons. Besides, the calculation of PAH flux during non water-sediment regulation based on only two samplings might result in the uncertainty of the annual PAH flux. However, according to previous research, there was no significant difference in PAH concentrations between dry and wet seasons (Lang et al., 2008; Li et al., 2006). Therefore, the uncertainty about the obtained annual PAH flux caused by the few samplings in this study might be negligible. In addition, Wang et al. (2007) estimated the PAH flux of the Yellow River to be 70.5 tons using the method that the riverine flux was assumed to positively correlate with the regional total emission of PAHs; this value was comparable to that obtained in our study. Water-sediment regulation of the Xiaolangdi Reservoir lasted for 22 days, accounting for $6.0 \%$ of the whole year. However, the contribution of PAH flux during water-sediment regulation to the annual flux was $35.7 \%(11.1 / 31.1 \times 100 \%)$.

\subsubsection{Comparison with other rivers}


As shown in Table 2, for the total dissolved concentrations of $\sum_{16} \mathrm{PAHs}$, the levels in the

397 Yellow River were much lower than those in the Jialing River (Xu et al., 2012), and were 398 comparable to the levels in the Seine River (Bourgeault and Gourlay-Francé, 2013) and at the 399 Datong station in the Yangtze River Estuary (Qi et al., 2014). However, the PAH levels in the 400 present study were much higher than those in the Pearl River Estuary (Wang et al., 2007), the 401 Niagara River (Michor et al., 1996), the Danube River (Maldonado et al., 1999), the lower reach 402 of the Mississippi River (Mitra and Bianchi, 2003), and the lower Brisbane River (Shaw et al., 403 2004). For the freely dissolved concentrations of $\sum_{16} \mathrm{PAHs}$, the levels in this study were much 404 higher than those in the Danube River (Vrana et al., 2014) and the Seine River (Bourgeault and 405 Gourlay-Francé, 2013), but were comparable to the levels in the Morava River (Prokeš et al., 406 2012), and were lower than the levels in the Willamette River (USA) (Sower and Anderson, 407 2008).

The concentrations of $\sum_{16} \mathrm{PAHs}$ in the SPS phase during water-sediment regulation ranged from 98 to $329 \mathrm{ng} / \mathrm{g}$, which were comparable to those (31-514 ng/g) in the upper and middle reaches of the Yellow River (Zhang and Zhang, 2010), and higher than those in the Danube River

411 Estuary (Maldonado et al., 1999). However, the concentrations of $\sum_{16} \mathrm{PAHs}$ in the SPS phase 412 obtained in the present research were much lower than those in the Pearl River Delta (Wang et al., 413 2007), in the Yangtze River (Qi et al., 2014), and in the Mississippi River (Mitra and Bianchi, 414 2003). Because the loess with low TOC contents contributes to $90 \%$ of the sediment of the 415 Yellow River, the TOC contents in the SPS obtained in this study were lower than those for other 416 rivers. Similar results about the Yellow River have been reported by other researchers (Li et al., 417 2006; Zhang et al., 2013). This might explain the lower PAH concentrations in the SPS of the 418 Yellow River than many other large rivers around the world.

419 Many researchers have reported the fluxes of $\sum_{16} \mathrm{PAHs}$ from rivers to seas. As shown in Table 420 4, the annual flux of PAHs of the Yellow River was lower than the Yangtze River (Qi et al., 2014) 
and Humen tidal channel (China) (Yang et al., 2004), but was comparable to the Heilongjiang River (Wang et al., 2007), the Pearl River (Wang et al., 2007), the Rhone River (Lipiatou et al., 1997), and the Mississippi River (Mitra and Bianchi, 2003; Wang et al., 2004). Furthermore, the contribution of the dissolved PAH flux to their total flux of the Yellow River was lower than that of the Yangtze River (Qi et al., 2014) and the Ebro River (Lipiatou et al., 1997), but was comparable to that of the Mississippi River.

\subsection{Effect of water-sediment regulation on the environmental risk of PAHs for}

\section{the Yellow River}

According to the results shown in section 3.3, the water discharge, sediment discharge, and PAH flux during the water-sediment regulation contributed to $22.6 \%, 32.4 \%$, and $35.7 \%$ of their annual discharges, respectively. Therefore, both the contribution ratios of sediment transport load and PAH flux during water-sediment regulation were higher than that of water discharge, indicating that the water-sediment regulation is beneficial to the ejection of sediment and PAHs from the Xiaolangdi Reservoir as well as downstream of the reservoir. Consequently, as to the long-term effect, the water-sediment regulation could reduce the retention of sediment and PAHs in the reservoir.

However, during the water-sediment regulation, the PAH concentrations in the water phase downstream of the reservoir were higher than those before and after the water-sediment regulation. This indicated that the water-sediment regulation of the Xiaolangdi Reservoir might increase the bioavailability of PAHs downstream of the reservoir as well as in the estuary during that period. In addition, the total dissolved concentration of each PAH in the river water was compared with its maximum permissible concentration (MPC) established by the Dutch Government, which could serve as a generic environmental quality standard (IWINS, 1997). The results indicated that the total dissolved concentrations of pyrene and benz(a)anthracene exceeded 
their MPCs at some sampling sites during the water-sediment regulation. Considering all the samplings at the six sites, $16.7 \%$ of the total dissolved benz(a)anthracene concentration exceeded its MPC during water regulation; $33.3 \%$ and $25.0 \%$ of pyrene and benz(a)anthracene exceeded their MPCs during sediment regulation, respectively (Figure 4). During water-sediment regulation, the freely dissolved PAH concentrations of the river water were 2-11 times higher than those before water-sediment regulation (Figure S8). This could increase the potential risk of fish and other organism exposure to PAHs in the river water.

This study suggested that the water-sediment regulation might reduce the environmental risk of PAHs in the reservoir in the long-term. However, a large amount of sediment would resuspend and release PAHs and other HOCs into the river water during water-sediment regulation, resulting in the increase of bioavailability and potential risk of PAHs as well as other HOCs to aquatic organisms downstream of the reservoir and in the estuary during that period. Therefore, the effect of water-sediment regulation on the bioavailability and environmental risk of PAHs as well as other contaminants should be considered in the operation and management of the Xiaolangdi Reservoir in the future.

\section{Acknowledgements}

This study was supported by the National Science Foundation for Innovative Research Group (No: 51421065), National Science Foundation for Distinguished Young Scholars (No: 51325902), and the National Science Foundation of China (No: 51279010).

\section{References}

Accardi-Dey, A.M., Gschwend, P.M., 2003. Reinterpreting literature sorption data considering both absorption into organic carbon and adsorption onto black carbon. Environ. Sci. Technol. 37(1), 99-106. DOI: 10.1021/es020569v 
Bourgeault, A., Gourlay-Francé, C., 2013. Monitoring PAH contamination in water: Comparison of biological and physico-chemical tools. Sci. Total. Environ. 454, 328-336. DOI:10.1016/j.scitotenv.2013.03.021

Chen, Y., Zhu, L., Zhou, R., 2007. Characterization and distribution of polycyclic aromatic hydrocarbon in surface water and sediment from Qiantang River, China. J. Hazard. Mater. 141, 148-155. DOI:10.1016/j.jhazmat.2006.06.106

Cornelissen, G., Arp, H.P.H., Pettersen, A., Pettersen, A., Hauge, A., Breedveld, G.D., 2008. Assessing PAH and PCB emissions from the relocation of harbor sediments using equilibrium passive samplers. Chemosphere. 72, 1581-1587. DOI:10.1016/j.chemosphere.2008.04.041

Deng, H., Peng, P.a., Huang, W., Song, J., 2006. Distribution and loadings of polycyclic aromatic hydrocarbons in the Xijiang River in Guangdong, South China. Chemosphere. 64, 1401-1411. DOI:10.1016/j.chemosphere.2005.12.027

Dong, J., Xia, X., Zhai, Y., 2013. Investigating particle concentration effects of polycyclic aromatic hydrocarbon (PAH) sorption on sediment considering the freely dissolved concentrations of PAHs. J. Soil. Sediment. 13, 1469-1477. DOI: 10.1007/s11368-013-0736-9

Durrieu de Madron, X., Ferre, B., Le Corre, G., Grenz, C., Conan, P., Pujo-Pay, M., Buscail, R., Bodiot, O., 2005. Trawling-induced resuspension and dispersal of muddy sediments and dissolved elements in the Gulf of Lion (NW Mediterranean). Cont. Shelf. Res. 25, 2387-2409. DOI:10.1016/j.csr.2005.08.002

Eggleton, J., Thomas, K.V., 2004. A review of factors affecting the release and bioavailability of contaminants during sediment disturbance events. Environ. Int. 30, 973-980. DOI:10.1016/j.envint.2004.03.001

Farooq, S., Eqani, S-A-M-A-S., Malik, R.N., et al. 2011. Occurrence, finger printing and ecological risk assessment of polycyclic aromatic hydrocarbons (PAHs) in the Chenab River, Pakistan. J. Environ. Monitor. 13, 3207-3215. DOI: 10.1039/C1EM10421G 
Feng, C., Xia, X., Shen, Z., Zhou, Z., 2007. Distribution and sources of polycyclic aromatic hydrocarbons in Wuhan section of the Yangtze River, China. Environ. Monit. Assess. 133, 447-458. DOI: 10.1007/s10661-006-9599-5

Feng, J., Shen, Z., Niu, J., Yang, Z., 2008. The role of sediment resuspension duration in release of PAHs. Chinese. Sci. Bull. 53, 2777-2782. DOI: 10.1007/s11434-008-0389-z

Fernandes, M., Sicre, M.-A., Boireau, A., Tronczynski, J., 1997. Polyaromatic hydrocarbon (PAH) distributions in the Seine River and its estuary. Mar. Pollut. Bull. 34, 857-867. DOI:10.1016/S0025-326X(97)00063-5

Ferré, B., Durrieu de Madron, X., Estournel, C., Ulses, C., Le Corre, G., 2008. Impact of natural (waves and currents) and anthropogenic (trawl) resuspension on the export of particulate matter to the open ocean: application to the Gulf of Lion (NW Mediterranean). Cont. Shelf. Res. 28, 2071-2091. DOI:10.1016/j.csr.2008.02.002

Friedman, C.L., Burgess, R.M., Perron, M.M., Cantwell, M.G., Ho, K.T., Lohmann, R., 2009. Comparing polychaete and polyethylene uptake to assess sediment resuspension effects on PCB bioavailability. Environ. Sci. Technol. 43, 2865-2870. DOI: 10.1021/es803695n

Gómez-Gutiérrez, A.I., Jover, E., Bodineau, L., Albaigés, J., Bayona, J.M., 2006. Organic contaminant loads into the Western Mediterranean Sea: estimate of Ebro River inputs. Chemosphere. 65, 224-236. DOI:10.1016/j.chemosphere.2006.02.058

Halfon, E., Allan, R.J., 1995. Modelling the fate of PCBs and Mirex in aquatic ecosystems using the TOXFATE model. Environ. Int. 21, 557-569. DOI:10.1016/0160-4120(95)00058-S

Hayes, D.F., Crockett, T.R., Ward, T.J., Averett, D., 2000. Sediment resuspension during cutterhead dredging operations. J. Waterw. Port. C-ASCE. 126, 153-161. DOI: 10.1061/(ASCE)0733-950X(2000)126:3(153)

Hu, P., Cao, Z., Pender, G., Tan, G., 2012. Numerical modelling of turbidity currents in the Xiaolangdi reservoir, Yellow River, China. J. Hydrol., 464: 41-53. DOI: 
Humborg, C., 1997. Primary productivity regime and nutrient removal in the Danube estuary. Estuar. Coast. Shelf. S. 45, 579-589. DOI: 10.1006/ecss.1997.0248

IWINS, 1997. Integrale Normstelling Stoffen. Milieukwaliteitsnormen bodem, water, lucht. Interdepartementale Werkgroep Integrale Normstelling Stoffen, VROM 97759/h/12-97. (In Dutch).

Je, C.H., Hayes, D.F., Kim, K.S., 2007. Simulation of resuspended sediments resulting from dredging operations by a numerical flocculent transport model. Chemosphere. 70, 187-195. DOI:10.1016/j.chemosphere.2007.06.033

Jonker, M.T.O., Muijs, B., 2010. Using solid phase micro extraction to determine salting-out (Setschenow) constants for hydrophobic organic chemicals. Chemosphere. 80, 223-227. DOI: 10.1016/j.chemosphere. 2010. 04.041

Lang, Y., Jia, Y., Liu, Z., Gao, Z., Wang, X., 2008. Seasonal distribution characteristics and sources of polycyclic aromatic hydrocarbons (PAHs) in water samples from the Yellow River Estuary. Periodical of Ocean University of China. 38, 640-646 (in Chinese).

Li, G., Xia, X., Yang, Z., Wang, R., Voulvoulis, N., 2006. Distribution and sources of polycyclic aromatic hydrocarbons in the middle and lower reaches of the Yellow River, China. Environ. Pollut. 144, 985-993. DOI: 10.1016/j.envpol.2006.01.047

Li, Z., Jiang, X., Jiang, Y., Li, L., Duan, J., 2005. Research on comparative measurement of discharge with ADCP and rotating element current meter. Automation in Water resources and Hydrology. 3, 31-37 (in Chinese).

Lipiatou, E., Tolosa, I., Simo, R., Bouloubassi, I., Dachs, J., Marti, S., Sicre, M.-A., Bayona, J., Grimalt, J., Saliott, A., 1997. Mass budget and dynamics of polycyclic aromatic hydrocarbons in the Mediterranean Sea. Deep-Sea. Res. Pt. II. 44, 881-905. DOI: 10.1016/S0967-0645(96)00093-8 
Liu, S., Xia, X., Yang, L., Shen, M., Liu, R., 2010. Polycyclic aromatic hydrocarbons in urban soils of different land uses in Beijing, China: Distribution, sources and their correlation with the city's urbanization history. J. Hazard. Mater. 177, 1085-1092. DOI: 10.1016/j.jhazmat.2010.01.032

Mackay, D., Hickie, B., 2000. Mass balance model of source apportionment, transport and fate of PAHs in Lac Saint Louis, Quebec. Chemosphere. 41, 681-692. DOI: $10.1016 / \mathrm{S} 0045-6535(99) 00486-5$

Maldonado, C., Bayona, J.M., Bodineau, L., 1999. Sources, distribution, and water column processes of aliphatic and polycyclic aromatic hydrocarbons in the northwestern Black Sea water. Environ. Sci. Technol. 33, 2693-2702. DOI: 10.1021/es9811647

Michor, G., Carron, J., Bruce, S., Cancilla, D.A., 1996. Analysis of 23 polynuclear aromatic hydrocarbons from natural water at the sub-ng/l level using solid-phase disk extraction and mass-selective detection. J. Chromatogr. A. 732, 85-99. DOI: 10.1016/0021-9673(95)01252-4

Mitra, S., Bianchi, T., 2003. A preliminary assessment of polycyclic aromatic hydrocarbon distributions in the lower Mississippi River and Gulf of Mexico. Mar. Chem. 82, 273-288. DOI: 10.1016/S0304-4203(03)00074-4

Nilsson, C., Reidy, C.A., Dynesius, M., Revenga, C., 2005. Fragmentation and flow regulation of the world's large river systems. Science. 308, 405-408. DOI: 10.1126/science.1107887

Pawliszyn, J., 1999. Applications of solid phase microextraction. ed. Royal Society of Chemistry, Combridge, UK, pp.129-130.

Pedersen, J.A., Schweitzer, L.E., Lin, C.H.M., Suffet, I., 2002. Effect of oxic state on nonpolar organic contaminant distribution, mobility, and bioavailability in estuarine sediments. Isr. J. Chem. 42, 109-118. DOI: 10.1560/569Q-NH11-LXPM-KH1Q

Prokeš, R., Vrana, B., Klánová, J., 2012. Levels and distribution of dissolved hydrophobic organic contaminants in the Morava river in Zlin district, Czech Republic as derived from 
their accumulation in silicone rubber passive samplers. Environ. Pollut. 166, 157-166. DOI: 10.1016/j.envpol.2012.02.022

Pusceddu, A., Grémare, A., Escoubeyrou, K., Amouroux, J., Fiordelmondo, C., Danovaro, R., 2005. Impact of natural (storm) and anthropogenic (trawling) sediment resuspension on particulate organic matter in coastal environments. Cont. Shelf. Res. 25, 2506-2520. DOI: 10.1016/j.csr.2005.08.012

Qi, W., Müller, B., Pernet-Coudrier, B., Singer, H., Liu, H., Qu, J., Berg, M., 2014. Organic micropollutants in the Yangtze River: Seasonal occurrence and annual loads. Sci. Total. Environ. 472, 789-799. doi:10.1016/j.scitotenv.2013.11.019

Schneider, A.R., Porter, E.T., Baker, J.E., 2007. Polychlorinated biphenyl release from resuspended Hudson River sediment. Environ. Sci. Technol. 41, 1097-1103. DOI: $10.1021 / \mathrm{es} 0607584$

Shaw, M., Tibbetts, I.R., Müller, J.F., 2004. Monitoring PAHs in the Brisbane River and Moreton Bay, Australia, using semipermeable membrane devices and EROD activity in yellowfin bream, Acanthopagrus australis. Chemosphere. 56, 237-246. DOI: 10.1016/j.chemosphere.2004.03.003

Sower, G.J., Anderson, K.A., 2008. Spatial and temporal variation of freely dissolved polycyclic aromatic hydrocarbons in an urban river undergoing superfund remediation. Environ. Sci. Technol. 42, 9065-9071. DOI: 10.1021/es801286z

Syvitski, J.P., Vörösmarty, C.J., Kettner, A.J., Green, P., 2005. Impact of humans on the flux of terrestrial sediment to the global coastal ocean. Science. 308, 376-380. DOI: 10.1126/science. 1109454

Vrana, B., Klučárová, V., Benická, E., Abou-Mrad, N., Amdany, R., Horáková, S., Draxler, A., Humer, F., Gans, O., 2014. Passive sampling: An effective method for monitoring seasonal and spatial variability of dissolved hydrophobic organic contaminants and metals in the 
594 Wang, F., Bu, Q., Xia, X., Shen, M., 2011. Contrasting effects of black carbon amendments on

Wang, J.-Z., Guan, Y.-F., Ni, H.-G., Luo, X.-L., Zeng, E.Y., 2007. Polycyclic aromatic hydrocarbons in riverine runoff of the Pearl River Delta (China): concentrations, fluxes, and fate. Environ. Sci. Technol. 41, 5614-5619. DOI: 10.1021/es070964r

Wang, X.-C., Chen, R.F., Gardner, G.B., 2004. Sources and transport of dissolved and particulate organic carbon in the Mississippi River estuary and adjacent coastal waters of the northern Gulf of Mexico. Mar. Chem. 89, 241-256. DOI: 10.1016/j.marchem.2004.02.014

Xia, X., Rabearisoa, A.H., Jiang, X., 2013b. Bioaccumulation of Perfluoroalkyl Substances by Daphnia magna in Water with Different Types and Concentrations of Protein. Environ. Sci. Technol. 47, 10955-10963. DOI: 10.1021/es401442y

Xia, X., Zhai, Y., Dong, J., 2013a. Contribution ratio of freely to total dissolved concentrations of polycyclic aromatic hydrocarbons in natural river waters. Chemosphere. 90, 1785-1793. DOI: 10.1016/j.chemosphere.2012.08.021

Xu, X.Y., Jiang, Z.Y., Wang, J.H., Zhu, H., 2012. Distribution and characterizing sources of polycyclic aromatic hydrocarbons of surface water from Jialing River. J. Cent. South Univ. 19, 850-854. DOI: 10.1007/s11771-012-1082-6

Yang, Q., Mai, B., Mo, J., Sheng, G., Luo, X., Lin, Z., 2004. Fluxes of Persistent Organic Pollutants from Humen Tidal Channel of Pearl River to Lingdingyang Estuary. Scientia Geographica Sinica. 24, 704-709 (in Chinese).

Yang, Z., Feng, J., Niu, J., Shen, Z., 2008. Release of polycyclic aromatic hydrocarbons from Yangtze River sediment cores during periods of simulated resuspension. Environ. pollut. 155, 
619 Zhang, H., Wang, S., 2012. Study on practices of water and sediment regulation mode for 620 Xiaolangdi Reservoir. Hongshui River, 102-105 (in Chinese).

621 Zhang, L., Wang, L., Cai, W., Liu, D., Yu, Z., 2013. Impact of human activities on organic carbon 622 transport in the Yellow River. Biogeosciences, 10, 2513-2524. DOI:10.5194/bg-10-2513-2013 623 Zhang, J., Zhang, L., 2010. Distribution and sources of polycyclic aromatic hydrocarbons in the 624 upper and middle reaches of the Yellow River in summer. Environmental Science and 625 Information Application Technology (ESIAT), 2010 International Conference on. IEEE, pp. 626 191-194. DOI: 10.1109/ESIAT.2010.5567307

627 Zhang, S., Zhang, Q., Darisaw, S., Ehie, O., Wang, G., 2007. Simultaneous quantification of 628 polycyclic aromatic hydrocarbons (PAHs), polychlorinated biphenyls (PCBs), and 629 pharmaceuticals and personal care products (PPCPs) in Mississippi river water, in New 630 Orleans, Louisiana, USA. Chemosphere. 66, 1057-1069. DOI: $631 \quad 10.1016 /$ j.chemosphere.2006.06.067 


\section{Figure captions}

634 Figure 1 Sampling sites of the Yellow River during water-sediment regulation (Reservoir 1:

635 Sanmenxia Reservoir; Reservoir 2: Xiaolangdi Reservoir; The blue line upstream the AS site is 636 the east line project of the South-to-North Water Diversion, which passes across the Yellow 637 River with a tunnel at $70 \mathrm{~m}$ beneath the riverbed of the Yellow River.)

638 Figure 2 Temporal variations of $\sum_{16} \mathrm{PAHs}$ in water and SPS phases at each site before and during 639 water and sediment regulation (A: before water-sediment regulation; B: during water regulation; 640 C: during sediment regulation, there was no data for JG and HYK because the SPS samples were 641 not much enough for the determination of PAHs during water regulation.)

642 Figure 3 Spatial variations of $\sum_{16} \mathrm{PAHs}$ in water and SPS phases during water-sediment 643 regulation (KQ: the PAH concentrations in the water of the reservoir; DA: the average PAH 644 concentrations of the six sampling sites downstream of the reservoir)

645 Figure 4 Comparison of dissolved concentrations of pyrene and benz(a)anthracene in river 646 water during water-sediment regulation and their maximum permissible concentrations (MPCs) 647 (the solid lines in the plots represent the MPCs of individual PAH) 


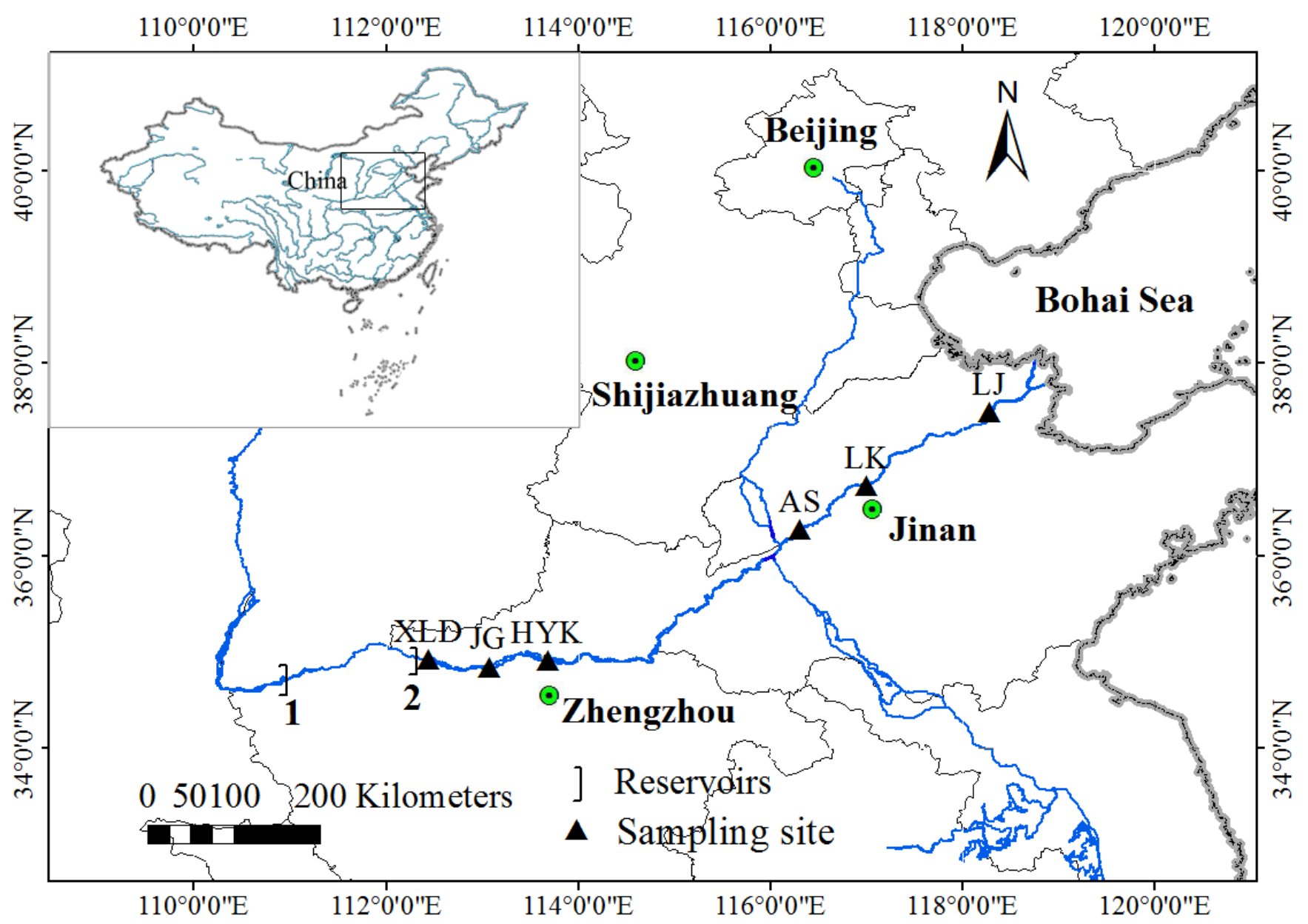

Figure 1 Sampling sites of the Yellow River during water-sediment regulation

651 (1: Sanmenxia Reservoir; 2: Xiaolangdi Reservoir (KQ); the blue line upstream the AS site is the 652 east line project of the South-to-North Water Diversion, which passes across the Yellow River with a tunnel at $70 \mathrm{~m}$ beneath the riverbed of the Yellow River.) 

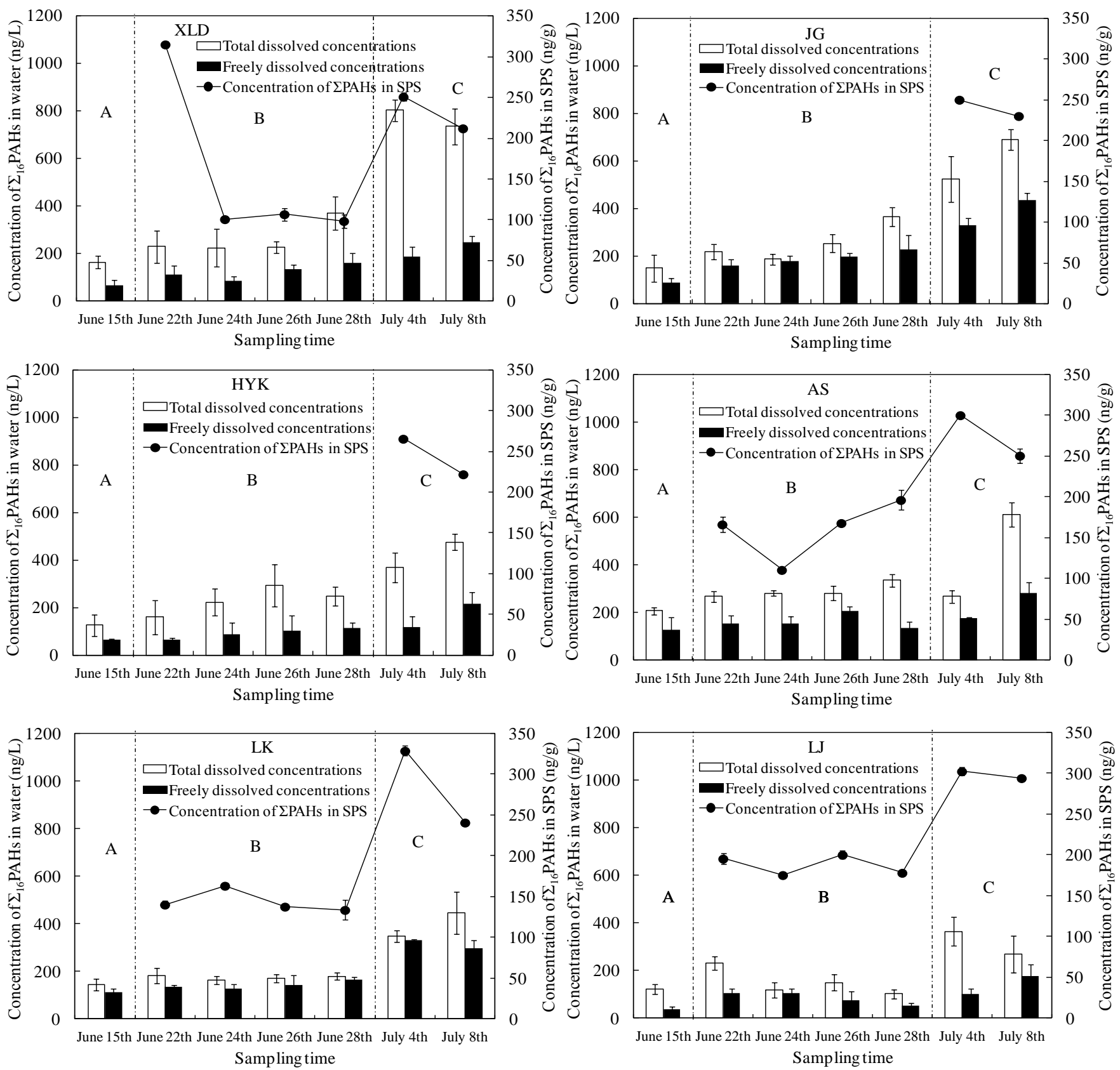

Figure 2 Temporal variations of $\sum_{16} \mathrm{PAHs}$ in water and SPS phases at each site before and during water-sediment regulation

658 (A: before water-sediment regulation; B: during water regulation; C: during sediment regulation.

659 There was no data for JG and HYK because the SPS samples were not much enough for the 660 determination of PAHs during water regulation.)

661 

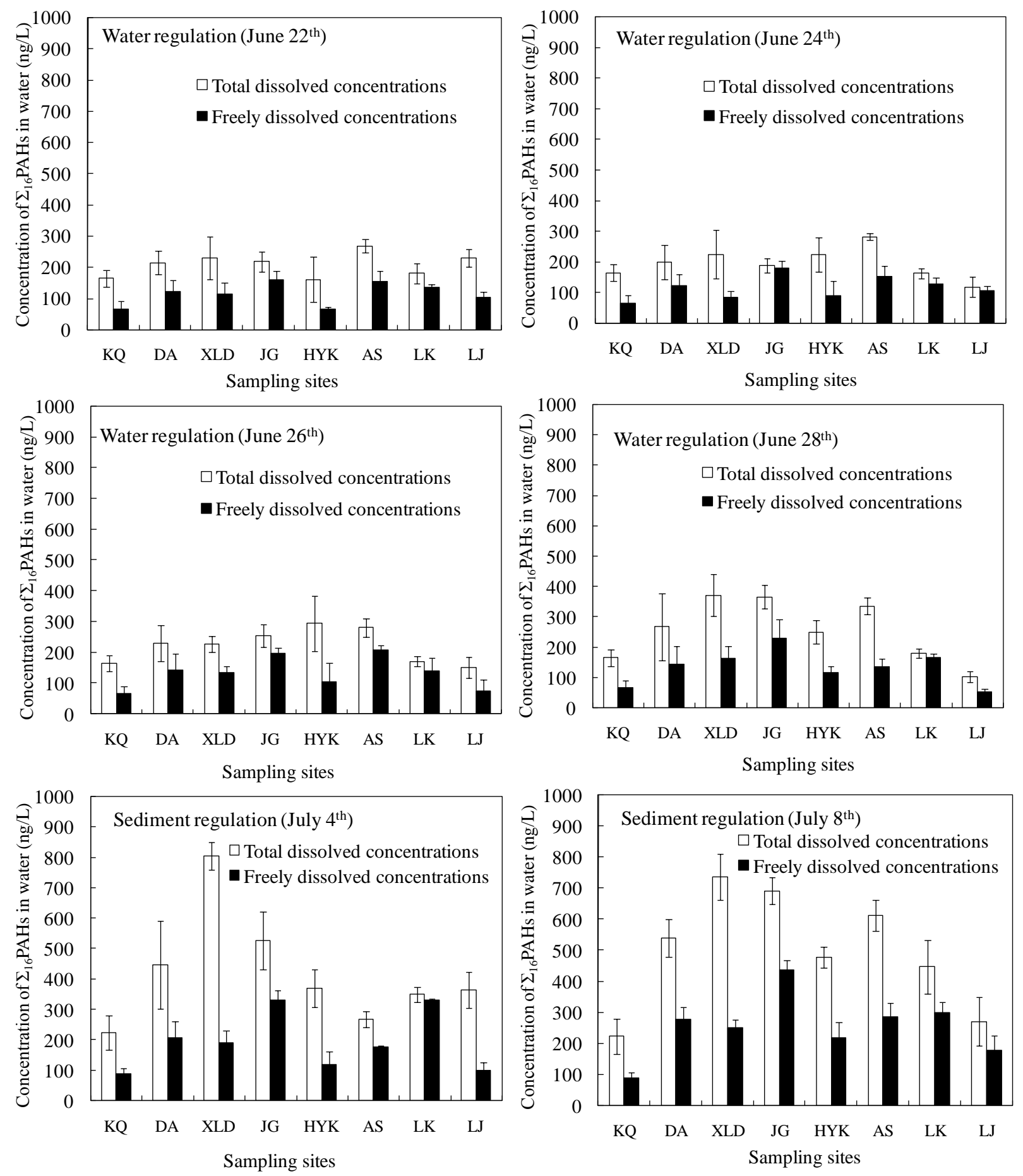

Figure 3 Spatial variations of $\sum_{16} \mathrm{PAHs}$ in water phases during water-sediment regulation (KQ: the PAH concentrations in the water of the reservoir; DA: the average PAH 666 concentrations of the six sampling sites downstream of the reservoir) 

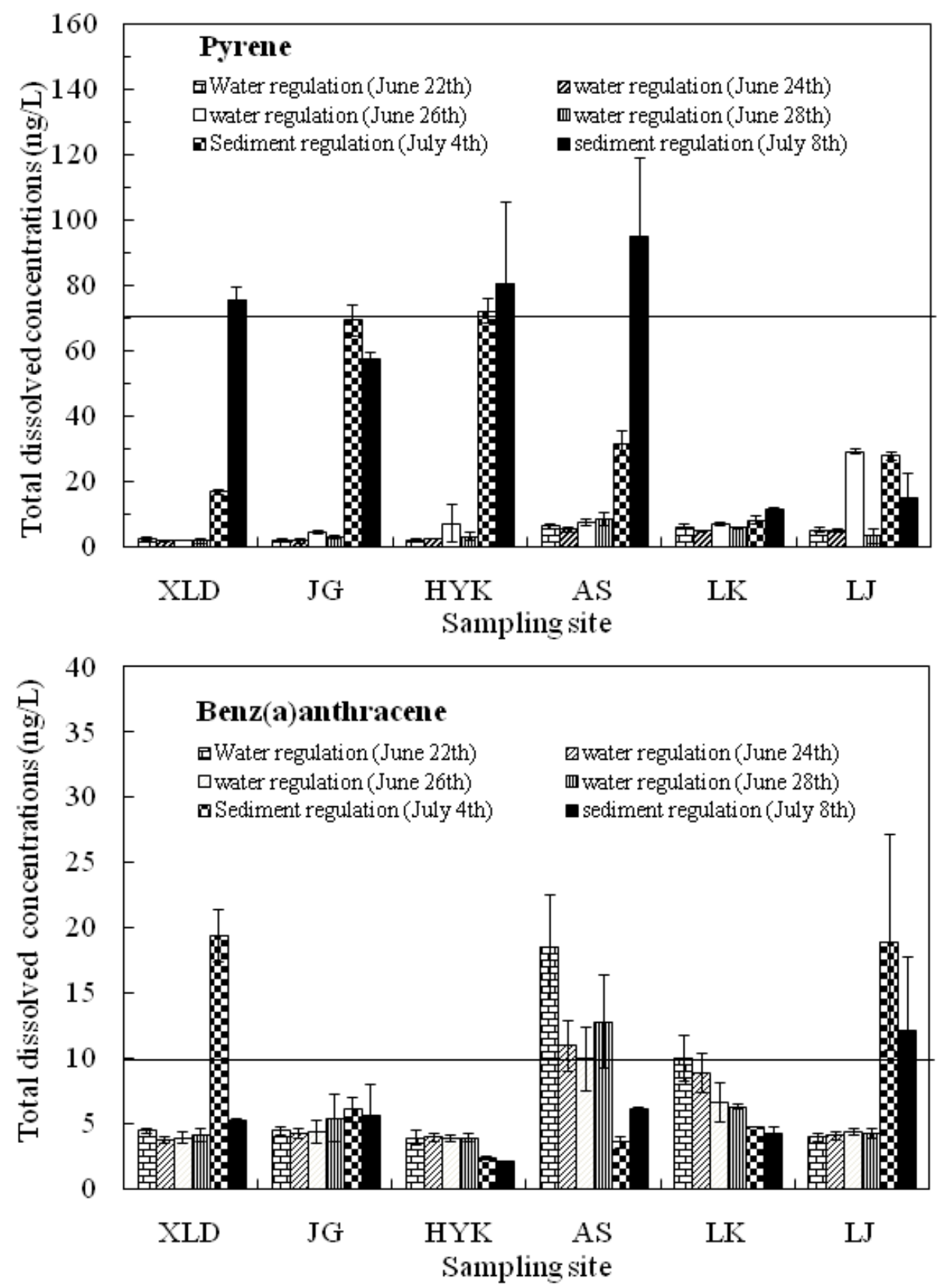

670 Figure 4 Comparison of dissolved concentrations of pyrene and benz(a)anthracene in river water during water-sediment regulation and their maximum permissible concentrations (MPCs) 


\begin{tabular}{|c|c|c|c|c|c|c|c|c|c|c|c|}
\hline \multirow{2}{*}{ Sampling site } & \multirow{2}{*}{$\begin{array}{l}\text { Distance from } \\
\text { Estuary }(\mathrm{km})\end{array}$} & \multicolumn{5}{|c|}{ Water regulation } & \multicolumn{5}{|c|}{ Sediment regulation } \\
\hline & & DOC (mg/L) & SPS (g/L) & $\mathrm{d}_{50}(\mu \mathrm{m})$ & TOC (\%o) & $\mathrm{BC}(\%)$ & DOC $(\mathrm{mg} / \mathrm{L})$ & SPS (g/L) & $\mathrm{d}_{50}(\mu \mathrm{m})$ & TOC (\%o) & BC (\%o) \\
\hline Xiaolangdi (XLD) & 864 & $5.27 \pm 2.68$ & $0.04 \pm 0.01$ & 77.5 & $0.94 \pm 0.72$ & $0.26 \pm 0.11$ & $6.91 \pm 0.05$ & $54.75 \pm 1.82$ & 30.8 & $3.03 \pm 0.14$ & $0.25 \pm 0.09$ \\
\hline Jiaogong (JG) & 788 & $5.54 \pm 2.69$ & $0.58 \pm 0.58$ & 36.6 & $1.54 \pm 0.44$ & $0.60 \pm 0.15$ & $6.69 \pm 0.14$ & $47.87 \pm 16.5$ & 27.3 & $3.62 \pm 1.06$ & $0.32 \pm 0.00$ \\
\hline Huayuankou (HYK) & 731 & $5.62 \pm 2.85$ & $0.09 \pm 0.03$ & 37.5 & $3.05 \pm 0.35$ & $0.55 \pm 0.27$ & $6.80 \pm 0.33$ & $20.61 \pm 0.16$ & 14.2 & $4.83 \pm 0.51$ & $0.34 \pm 0.04$ \\
\hline Aishan (AS) & 402 & $6.76 \pm 0.43$ & $5.01 \pm 2.24$ & 27.0 & $2.22 \pm 0.26$ & $0.63 \pm 0.28$ & $6.39 \pm 0.62$ & $18.29 \pm 6.19$ & 12.3 & $3.63 \pm 0.30$ & $0.41 \pm 0.09$ \\
\hline Luokou (LK) & 298 & $6.82 \pm 0.44$ & $5.14 \pm 1.57$ & 31.9 & $2.00 \pm 0.25$ & $1.10 \pm 0.27$ & $6.13 \pm 1.03$ & $15.11 \pm 4.65$ & 11.1 & $3.82 \pm 0.97$ & $0.30 \pm 0.05$ \\
\hline Lijin (LJ) & 104 & $7.12 \pm 0.41$ & $10.05 \pm 0.54$ & 17.0 & $3.22 \pm 0.67$ & $2.74 \pm 0.68$ & $6.00 \pm 0.51$ & $19.02 \pm 7.09$ & 12.5 & $4.64 \pm 0.01$ & $0.34 \pm 0.03$ \\
\hline
\end{tabular}

675 
Table 2 Comparison of PAHs level in the Yellow River with other rivers around the world

\begin{tabular}{|c|c|c|c|c|}
\hline \multirow{2}{*}{ River name (Country) } & \multicolumn{2}{|c|}{ Dissolved PAH concentration in water phase } & \multirow{2}{*}{$\begin{array}{l}\sum_{16} \mathrm{PAHs} \text { in SPS } \\
\text { SPS (ng/g) }\end{array}$} & \multirow[b]{2}{*}{ references } \\
\hline & Total (ng/L) & freely $(\mathrm{ng} / \mathrm{L})$ & & \\
\hline \multirow{2}{*}{ Yellow River (China) } & $101-803$ & $66.2-468$ & $98.1-329$ & In this study (during water-sediment regulation) \\
\hline & $121-208$ & $38.0-128$ & & In this study (before water-sediment regulation) \\
\hline Yellow River (China) & 179-369 & & $54.3-154.5$ & Li et al., 2006 (in the middle and lower reaches) \\
\hline Yellow River (China) & $96.6-476.84$ & & $31-514$ & Zhang and Zhang, 2010 (in the upper and middle reaches) \\
\hline Yangtze River (China) & $320-630$ & & $1830-9150$ & Qi et al., 2014 (at Datong station) \\
\hline Yangtze River (China) & $242-6345$ & & 4677 & Feng et al., 2007 (in Wuhan section) \\
\hline Jialing River (China) & $812-1586$ & & & Xu et al., 2012 \\
\hline Pearl River (China) & $10.8-323$ & & $100-3840$ & Wang et al., 2007 \\
\hline Brisbane River (Australia) & $5-12$ & & & Shaw et al., 2004 \\
\hline Mississippi River (USA) & $12-77$ & & $1100-7000$ & Mitra and Bianchi, 2003 (in the lower reach) \\
\hline Mississippi River (USA) & $62.9-114.7$ & & & Zhang et al., 2007 \\
\hline Niagara River (Canada) & 16.8 & & & Michor et al., 1996 \\
\hline Danube River Estuary & 1.30 & & $0.5-5.6$ & Maldonado et al., 1999 \\
\hline $\begin{array}{l}\text { Danube River } \\
\text { (Austria and Slovakia) }\end{array}$ & & $5-72$ & & Vrana et al., 2014 \\
\hline Seine River (France) & $8.9-271.8$ & $3.5-105.9$ & $4000-64000$ & Bourgeault and Gourlay-Francé, 2013 \\
\hline Morava River (Czech Republic) & & $25-203$ & & Prokeš et al., 2012 \\
\hline Willamette River (USA) & & $440 \pm 422$ & & Sower and Anderson, 2008 \\
\hline
\end{tabular}


Table 3 The $\log K_{O C}$ (OC-normalized distribution coefficient) values of PAHs during water-sediment regulation at each site

\begin{tabular}{|c|c|c|c|c|c|c|c|c|c|c|c|c|c|}
\hline \multirow{2}{*}{ PAHs } & \multirow{2}{*}{$\log K_{O W}$} & \multicolumn{7}{|c|}{$\log K_{O C}$ (During water regulation) } & \multicolumn{5}{|c|}{$\log K_{O C}$ (During sediment regulation) } \\
\hline & & XLD & AS & LK & $\mathrm{LJ}$ & Mean & XLD & JG & HYK & AS & LK & $\mathrm{LJ}$ & Mean \\
\hline Nap & 3.3 & 4.78 & 4.36 & 4.90 & 4.73 & 4.69 & 4.52 & 4.15 & 4.04 & 4.26 & 4.48 & 4.72 & 4.36 \\
\hline Acy & 3.94 & 5.73 & 5.17 & 5.42 & 5.60 & 5.48 & 5.71 & 5.62 & 5.83 & 5.35 & 5.31 & 5.66 & 5.58 \\
\hline Ace & 4.03 & 5.43 & 4.95 & 5.25 & 5.51 & 5.29 & 5.23 & 4.79 & 5.15 & 4.92 & 5.01 & 5.35 & 5.08 \\
\hline Fle & 4.18 & 5.47 & 5.14 & 5.37 & 5.66 & 5.41 & 5.32 & 4.99 & 5.33 & 5.35 & 5.24 & 5.71 & 5.32 \\
\hline Phe & 4.57 & 6.14 & 5.54 & 5.78 & 5.99 & 5.86 & 5.77 & 5.29 & 5.49 & 5.63 & 5.50 & 5.88 & 5.59 \\
\hline Ant & 4.54 & 5.61 & 5.27 & 5.33 & 5.71 & 5.48 & 5.00 & 4.72 & 5.23 & 5.19 & 5.02 & 5.07 & 5.04 \\
\hline Flu & 5.22 & 6.18 & 5.61 & 5.63 & 6.11 & 5.88 & 5.52 & 5.15 & 5.45 & 5.40 & 5.36 & 6.08 & 5.49 \\
\hline Pyr & 5.18 & 6.23 & 6.28 & 6.39 & 6.07 & 6.24 & 5.91 & 4.72 & 4.46 & 5.40 & 5.82 & 5.69 & 5.33 \\
\hline $\mathrm{BaA}$ & 5.61 & 6.54 & 5.69 & 5.41 & 5.39 & 5.76 & 6.15 & 5.68 & 5.79 & 5.61 & 5.59 & 5.38 & 5.70 \\
\hline $\mathrm{Chr}$ & 5.91 & 6.04 & 5.06 & 5.30 & 5.86 & 5.57 & 5.92 & 5.86 & 5.82 & 5.47 & 5.63 & 5.70 & 5.73 \\
\hline
\end{tabular}

681

682

683 


\begin{tabular}{|c|c|c|c|c|c|c|c|}
\hline \multirow[b]{2}{*}{ River name (Country) } & \multirow{2}{*}{$\begin{array}{l}\text { Water } \\
\text { discharge } \\
\left(10^{9} \mathrm{~m}^{3} / \mathrm{yr}\right)\end{array}$} & \multirow[b]{2}{*}{ SPS (mg/L) } & \multicolumn{4}{|c|}{ PAH flux (t/yr) } & \multirow[b]{2}{*}{ references } \\
\hline & & & total & particulate & dissolved & dissolved/total $(\%)$ & \\
\hline Yellow River (China) & 5.25 & $20-5.96 \times 10^{4}$ & 11.1 & 10.03 & 1.06 & 9.5 & in this study (during water-sediment regulation) \\
\hline Yellow River (China) & 23.5 & & 31.1 & 26.6 & 4.5 & 14.4 & in this study (annual flux) \\
\hline Yellow River (China) & 57 & & 70.5 & & & & Wang et al., 2007 \\
\hline Yangtze River (China) & 980 & & 368.9 & & & About 50 & Qi et al., 2014 \\
\hline Heilongjiang River (China) & 350 & & 30.2 & & & & Wang et al., 2007 \\
\hline Xijiang River (China) & & & 19.4 & & & & Deng et al., 2006 \\
\hline Pearl River (China) & 350 & & 33.9 & & & & Wang et al., 2007 \\
\hline Humen tidal channel (China) & & & 247.9 & 13.8 & 234.1 & 94.4 & Yang et al., 2004 \\
\hline Qiantang River (China) & 9.48 & & & & 11.4 & & Chen et al., 2007 \\
\hline Mississippi River (USA) & 58 & & 28.2 & 25.2 & 3.0 & 10.6 & Mitra and Bianchi, 2003; Wang et al., 2004 \\
\hline Seine River (France) & 13.7 & $9-17$ & 8.4 & 0.27 & 8.14 & 96.8 & Fernandes et al., 1997 \\
\hline Rhone River (France) & 53.9 & & 7.4-33 & $5.8-29$ & 1.6 & $5.2-21.6$ & Lipiatou et al., 1997; Gómez-Gutiérrez et al., 2006 \\
\hline St. Lawrence River (Canada) & & & 6.5 & & & & Mackay and Hickie, 2000 \\
\hline Niagara River (USA, Canada) & 18.9 & & 3.2 & & & & Michor et al., 1996; Halfon and Allan, 1995 \\
\hline Danube River (Europe) & 210 & & 0.3 & & & & Humborg, 1997; Maldonado et al., 1999 \\
\hline Ebro River (Spain) & 9.3 & & 1.3 & 0.9 & 0.4 & 30.8 & Lipiatou et al., 1997; Gómez-Gutiérrez et al., 2006 \\
\hline Chenab River (Pakistan) & 59 & & 52.8 & & & & Farooq et al., 2011 \\
\hline
\end{tabular}


686 Graphical Abstract

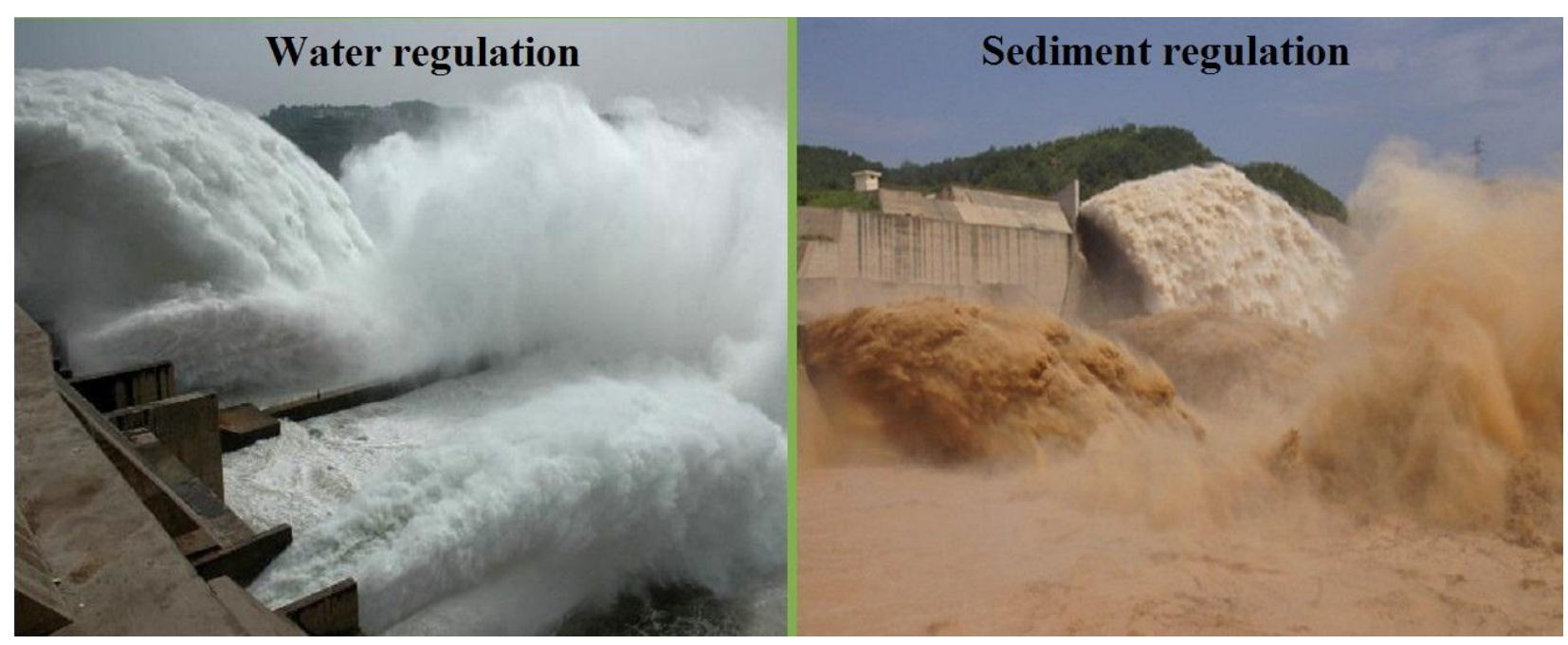

687 